\title{
NEURONAL MIGRATION DISORDER
}

Revathi $K^{1}$, Sivaraman $S^{2}$, Raghavendran V. $D^{3}$

1 Post Graduate, Department of Paediatrics, SMVMCH.

${ }^{2}$ Post Graduate, Department of Paediatrics, SMVMCH.

3 Professor and HOD, Department of Paediatrics, SMVMCH.

\section{ABSTRACT}

A 3-year-old female child admitted for assessment of developmental delay. No family history of developmental problem. History of third degree consanguinity. Anthropometry:-height $-90 \mathrm{cms}$ (15th centile), weight - $12.5 \mathrm{~kg}(<15 \mathrm{th}$ centile), Head circumference$44 \mathrm{cms}$ ( $<3 \mathrm{rd}$ centile). On examination shows hypertonia of lower limb extensors, DTR exaggerated, power $4 / 5$ of distal muscles of lower limb and bilateral plantar extensor response. Developmental age is 1 year by using Denver scale. Developmental Quotient for the Child is 33. MRI study showed Grey matter heterotopia of subcortical region in posterior lobe.

\section{KEYWORDS}

Neuronal Migration Disorder, Band Heterotopia.

HOW TO CITE THIS ARTICLE: Revathi K, Sivaraman S, Raghavendran V. D. "Neuronal Migration Disorder." Journal of Evolution of Medical and Dental Sciences 2015; Vol. 4, Issue 102, December 21; Page: 16808-16809, D0I: 10.14260/jemds/2015/2522

\section{INTRODUCTION}

Development of central nervous system is a highly complicated process and is organized in the following steps: primary neural tube formation starts at 3-4 weeks of gestation, followed by prosencephalic development occurs at 2-3 months of gestation, neuronal proliferation starts at 3-4 months of gestation and neuronal migration at the age of 3-5 months followed by organization starts from 5 months of gestation to birth and myelination after the birth will occur. We are presenting a case of neuronal migration disorders.

\section{CASE REPORT}

A 3-year-old female child admitted for assessment of developmental delay. This is the second child in the family, elder sibling is a male child and is developmentally normal, no family history of developmental problem. History of third degree consanguinity. Antenatal history was uneventful. Normal vaginal delivery, neonatal period was uneventful. Anthropometry:-height $-90 \mathrm{cms}$ (15th centile), weight - $12.5 \mathrm{~kg}$ ( $<15$ th centile), Head circumference- $44 \mathrm{cms}(<3 \mathrm{rd}$ centile). The child is conscious and cranial nerve examination revealed convergent squint and motor system examination shows hypertonia of lower limb extensors. DTR exaggerated with diminished power $4 / 5$ of distal muscles of lower limb. Bilateral plantar extensor response. Developmental age is 1 year by using Denver scale. Developmental Quotient for the Child is 33. MRI is done.

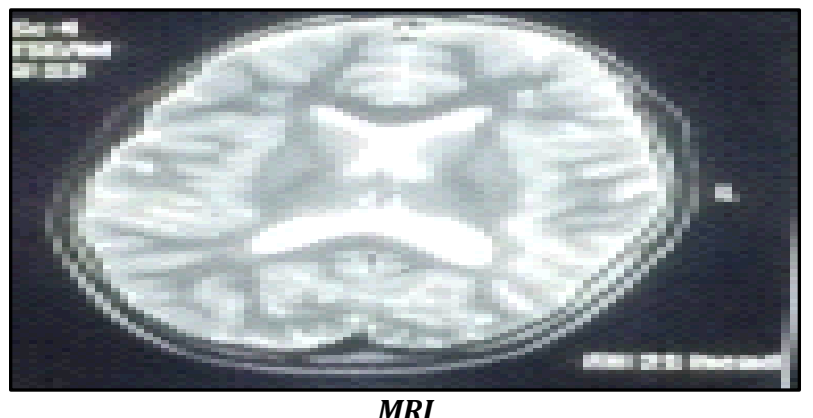

\section{MRI}

Financial or Other, Competing Interest: None.

Submission 16-11-2015, Peer Review 17-11-2015,

Acceptance 14-12-2015, Published 21-12-2015.

Corresponding Author:

Dr. Revathi $K$,

No. 24, Chozhan Nagar, Uzhanthai Keeraipalayam,

Mudaliarpet, Pondicherry-605004.

E-mail: revathikrishnakumar.1990@gmail.com DOI:10.14260/jemds/2015/2522

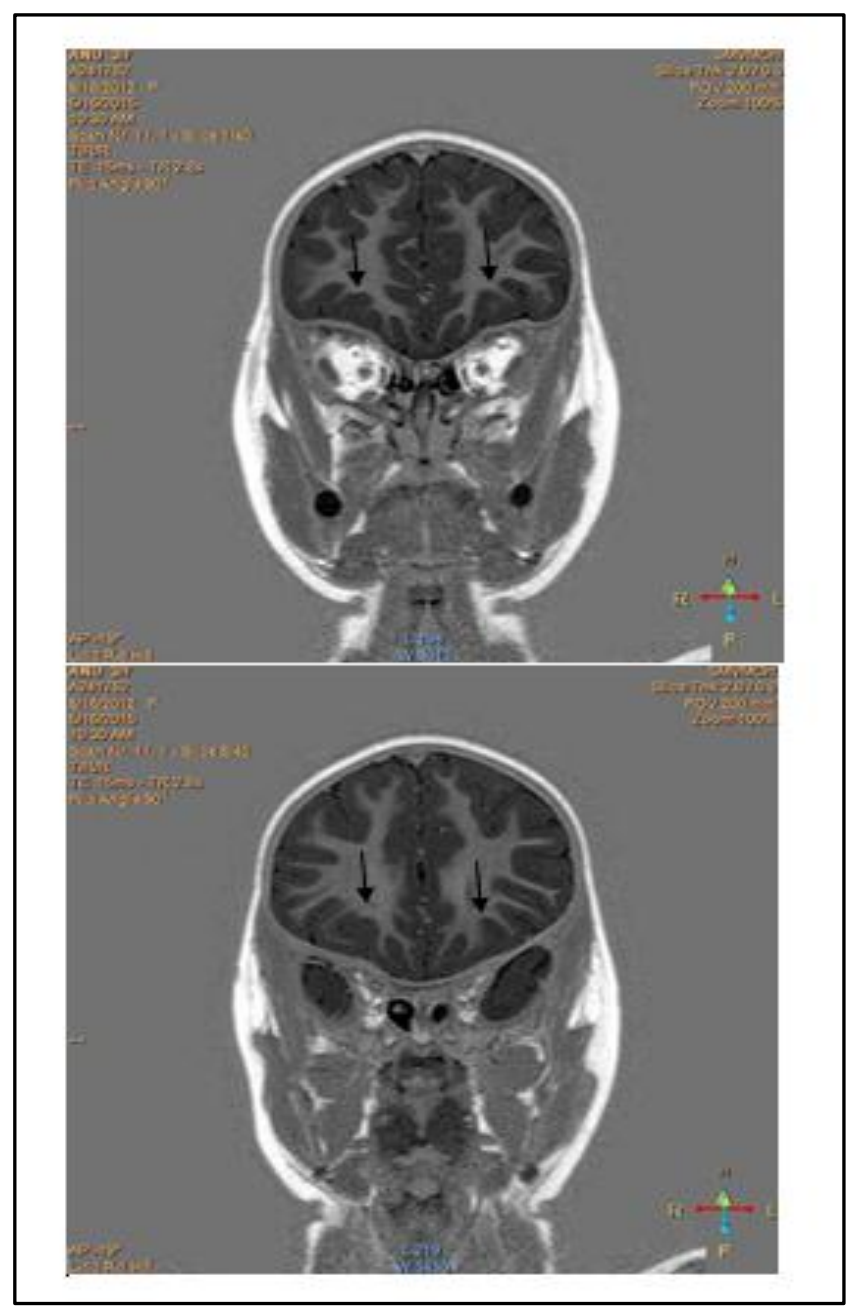

MRI: Study showed Grey matter heterotopia of subcortical region in posterior lobe

\section{DISCUSSION}

The development of cerebral cortex results from complex sequential process of cell proliferation, cell migration, cortical organization and formation of neuronal cortex. Grey matter heterotopia is a group of neuronal disorder characterized by ectopic position of neurons. Affected patient are generally classified into two groups, depending on location of formation. 
1. Periventricular heterotopia: a) Periventricular Nodular Heterotopia (PNH), b) Periventricular laminar heterotopia, c) Ribbon like heterotopia.

2. Subcortical heterotopia: Subcortical Band Heterotopia falls under lissencephaly spectrum of heterotopia.[1,2,3 Periventricular heterotopia - mutation in FLNA gene on Xq28 were found on $100 \%$ of families with $\mathrm{X}$ linked bilateral periventricular nodular heterotopia and $26 \%$ of sporadic cases with coagulopathy and cardiovascular malformation may be associated.[4] Mutation in the gene locus ARFGEF2 (20q 13.13) present with $\mathrm{PNH}$ with microcephaly. Mutation in gene (C6 orf 70 6q27, FAT4 (4q-28.1), DCHS1 (11p15.4) are other genes associated with $\mathrm{PNH}$.

In subcortical heterotopia (other than band heterotopia or cortical infolding), no cause has been identified. They can present as, 1. Curvilinear transformed heterotopia with thinning of overlying cortex with or without basal ganglia anomalies. 2. Multinodular heterotopia with thin overlying cortex. 3. Transmantle columnar heterotopic with or without PNH. Heterotopia are most commonly isolated anomalies, but may be part of number of syndromes including chromosamal anomalies and fetal exposure to toxins include alcohol.[4]
Subcortical heterotopia may present with epilepsy in both men and women. The more extreme heterotopia, the greater the CNS deficit. Bilateral heterotopia is associated with severely developmental delay or mental retardation. Epilepsy associated with grey matter heterotopia is frequently resistent to medication. Epileptogenic foci has not been identified in these patients. It is proposed that reactive changes in periectopic areas are instrumental. It precludes surgery. ${ }^{[4]}$

\section{REFERENCES}

1. Cardoso C, Boys A, Parrini E, et al. Periventricular heterotopia, mental retardation and epilepsy associated with 5q14.3-q15 deletion Neurology 2009;72:784-92.

2. Garbelli R, Rossini L, Moroni RF, Watakabe A, Yamamori T, Tassi L, et al. Layer-specific genes reveal a rudimentary laminar pattern in human nodular heterotopia. Neurology 2009;73:746-53.

3. Barkovich AJ, Guerrini R, Kuzniecky RI, et al. "A developmental and genetic classification for malformations of cortical development: update 2012. Brain 2012.10.1093/brain/aws019.

4. Watrin F, Manent Bernard J, Cardoso C, et al. Causes and consequences of gray matter heterotopia. CNS neuroscience and therapeutics 2015;21:112-122. 